\title{
The fetus or the infant - which is the father of the man? (both)
}

\begin{tabular}{|r|l|}
\hline Journal: & American Journal of Respiratory and Critical Care Medicine \\
\hline Manuscript ID & Draft \\
\hline Manuscript Type: & ED - Editorial \\
\hline Date Submitted by the Author: & n/a \\
\hline Complete List of Authors: & $\begin{array}{l}\text { Turner, Stephen; University of Aberdeen, Department of Child Health } \\
\text { Devereux, Graham; University of Aberdeen, Child Health }\end{array}$ \\
\hline Subject Category: & 1.17 Epidemiology (Pediatric): Risk Factors < ASTHMA \\
\hline Keywords: & Longitudinal studies, Obstructive airways disease, Fetus \\
\hline & \multicolumn{2}{|l}{} \\
\hline
\end{tabular}

SCHOLARONE ${ }^{m}$

Manuscripts 


\section{Page 1 of 5}

The fetus or the infant - which is the father of the man? (both)

Steve Turner, Graham Devereux

Child Health, University of Aberdeen

Contact details. Prof S Turner, Child Health, Royal Aberdeen Children's Hospital, Aberdeen, UK, AB25 9BZ 
A $35 \mathrm{~mm}$ slide showing the Fletcher-Peto graph was a key element in the carousel used for teaching medical students life course epidemiology in respiratory medicine. The slide tracked various downwards trajectories in lung function from a peak of $100 \%$ at approximately age 25 years of age. Life does not begin at 25 , but it has taken several decades for birth cohorts to map lung function trajectories from early life to adulthood. These cohorts have led to the "modern" Fletcher-Peto curve which has a number of upwards trajectories from 0-25 years of age (Figure) some of which attain a "normal" $100 \%$ but some fall short of this peak through more than one trajectory. The height of the peak in lung function achieved is a measure of respiratory "reserve" against fixed airways disease in later life. We are going to have to wait another 25 years for the birth cohorts to show whether those who fail to attain "normal" lung function are at increased risk for chronic obstructive pulmonary disease (COPD), but in the meantime we can reasonably assume that this hypothesis will be proven thanks to a cohort where reduced lung function in the first decade of life has been associated with increased risk of COPD in the sixth decade(1).

What is still not clear is when the gradient of the upwards trajectory in lung function is determined and what might be done to alter it. A paper in this edition has shed light on the very early origins of lung function (2). What was previously understood was that, at a population level, low lung function in the first two months was weakly predictive of lung function in early adulthood $(3,4)$, and that low lung function in some infants may apparently resolve but persists in those with a family history of asthma or early onset atopy (5). Work from other cohorts indicate that the development of asthma may lead to "deterioration" in lung function between early infancy and seven years of age (6) whilst improved air quality may lead to improved growth of lung function between ages 11 and 15 years (7). An additional factor associated with changing trajectory of lung function in early life is post-natal weight gain (8). Accelerated postnatal growth may occur de novo or may represent "catch up" growth after suppressed antenatal growth, and any intervention aimed at influencing lung function outcome needs to understand whether to target the antenatal or post-natal period.

The novelty of the study by den Dekker et al (2) is that it demonstrates two pathways to airway obstruction at ten years of age (i.e. reduced $\mathrm{FEV}_{1} / \mathrm{FVC}$ ratio). Restricted antenatal growth (defined as a 0.67 reduction in z score) which is followed by normal or accelerated ("catch up") postnatal growth is associated with reduced $\mathrm{FEV}_{1} / \mathrm{FVC}$ ratio due to a reduction in $\mathrm{FEV}_{1}$ relative to $\mathrm{FVC}$; interestingly, ongoing postnatal growth restriction is not associated with airways obstruction. The second "pathway to airway obstruction" is one where accelerated antenatal growth is maintained during infancy, and here the mechanism is due to a greater increase in FVC relative to $\mathrm{FEV}_{1}$.

This paper (2) is the latest in many important papers from the Generation R cohort (9), and its main strength is the intense focus on growth between the second trimester and the first birthday. A second strength is that the sample size of 5635 is large enough to place individuals into discrete growth categories whilst allowing for the inevitable missingness of data. No study is perfect, and the Generation R cohort did not measure infant lung function so we are blind to any possible change in neonatal lung function trajectory associated with change in weight. A second relative limitation is that the clinical relevance of early growth patterns is not clear in this cohort since the groups with reduced $\mathrm{FEV}_{1} / \mathrm{FVC}$ were not at increased risk for asthma; restricted postnatal weight gain was associated with a borderline increased risk for asthma. A further limitation is that post bronchodilator lung function was not determined so we do not know whether the reduced $F E V_{1} / F V C$ ratio is fixed or reversible. 
The work from the Generation R cohort and others continues to give insight into the early origins of non-communicable diseases (NCD) in adulthood, including COPD, ischaemic heart disease and type II diabetes mellitus. The 1995 "fetal origins" hypothesis (10) considered the relationship between fetal exposures and risk for NCDs, whilst the 2004 concept of "developmental plasticity" (11) considered how the antenatal and postnatal environment both contribute to phenotype. The observations described in the present study (2) are consistent with the model of developmental plasticity since both antenatal and postnatal growth had implications for obstructive lung function. The results presented here (2) are also possibly the first to demonstrate that the same phenotype can be reached via different pathways.

So where do we go from here? The importance of maternal health and wellbeing during pregnancy and early feeding practice to NCD risk in offspring has long been recognised (12). These findings add to the mountain of evidence that there is a window of opportunity to intervene and prevent obstructive airway disease, and this window is relatively wide open during the thousand days between conception and the second birthday. The burden of COPD is rising and in the FEV $1 / F V C$ ratio we have an outcome which can be measured many years before COPD symptoms emerge, interventions which involve optimising nutrition and air quality are now required to reduce COPD prevalence in 2100 . 
Figure legend. Schematic diagram illustrating a number of pathways to "normal" and "abnormal" lung function. The two solid lines indicate fixed trajectories throughout the lifecourse from conception to 25 year of age. The dashed line corresponds to those individuals whose lung function changes from "reduced" to "normal". The dotted line tracks those whose lung function is initially "normal" but becomes "abnormal".

\section{REFERENCES}

(1) Tai A, Tran H, Roberts M, Clark N, Wilson J, Robertson CF. The association between childhood asthma and adult chronic obstructive pulmonary disease. Thorax 2014;9:805.

(2) den Dekker H, Jaddoe V, Reiss I, de Jongste JC, Duijts L. Fetal and infant growth patterns and risk of lower lung function and asthma. The Generation R Study. Am J Respir Crit Care Med 2017.

(3) Stern DA, Morgan WJ, Wright AL, Guerra S, Martinez FD. Poor airway function in early infancy and lung function by age 22 years: a non-selective longitudinal cohort study. Lancet 2007;370:758764.

(4) Mullane D, Turner SW, Cox DW, Goldblatt J, Landau LI, le Souef PN. Reduced infant lung function, active smoking, and wheeze in 18-year-old individuals. JAMA Pediatrics 2013;167:368-373.

(5) Turner S, Fielding S, Mullane D, Cox D, Goldblatt J, Landau LI, le Souef PN. A longitudinal study of lung function from 1 month to 18 years of age. Thorax 2014;69:1015.

(6) Bisgaard $\mathrm{H}$, Jensen $\mathrm{SM}$, Bonnelykke $\mathrm{K}$. Interaction between asthma and lung function growth in early life. American Journal of Respiratory \& Critical Care Medicine 2012;185:1183-1189.

(7) Gauderman WJ, Urman R, Avol E, Berhane K, McConnell R, Rappaport E, Chang R, Lurmann F, Gilliland F. Association of improved air quality with lung development in children. N Engl J Med 2015;372:905-913.

(8) Turner S, Zhang G, Young S, Cox M, Goldblatt J, Landau L, Le Souef P. Associations between postnatal weight gain, change in postnatal pulmonary function, formula feeding and early asthma. Thorax 2008;63:234-239.

(9) Kooijman MN, Kruithof CJ, van Duijn CM, Duijts L, Franco OH, van IJzendoorn MH, de Jongste JC, Klaver CCW, van der Lugt A, Mackenbach JP, Moll HA, Peeters RP, Raat H, Rings EHHM, Rivadeneira $F$, van der Schroeff MP, Steegers EAP, Tiemeier H, Uitterlinden AG, Verhulst FC, Wolvius E, Felix JF, Jaddoe VWV. The Generation R Study: design and cohort update 2017. Eur J Epidemiol 2016;31:1243-1264.

(10) Barker DJ. Fetal origins of coronary heart disease. BMJ 1995;311:171-174.

(11) Bateson P, Barker D, Clutton-Brock T, Deb D, D'Udine B, Foley RA, Gluckman P, Godfrey K, Kirkwood T, Lahr MM, McNamara J, Metcalfe NB, Monaghan P, Spencer HG, Sultan SE. Developmental plasticity and human health. Nature 2004;430:419-421.

(12) Barker DJ, Osmond C. Inequalities in health in Britain: specific explanations in three Lancashire towns. British Medical Journal Clinical Research Ed 1987;294:749-752. 


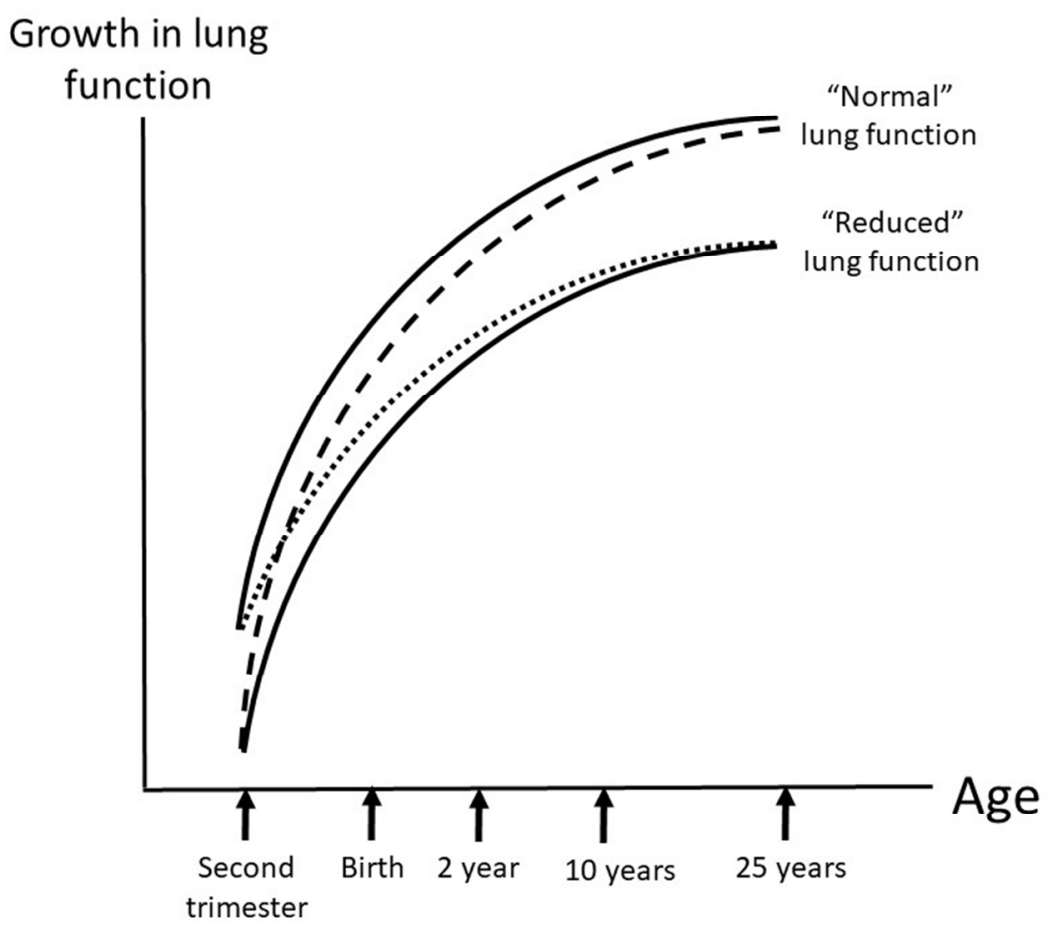

Figure legend. Schematic diagram illustrating a number of pathways to "normal" and "abnormal" lung function. The two solid lines indicate fixed trajectories throughout the lifecourse from conception to 25 year of age. The dashed line corresponds to those individuals whose lung function changes from "reduced" to "normal". The dotted line tracks those whose lung function is initially "normal" but becomes "abnormal". 